\title{
ANÁLISE DO USO DO SOLO URBANO E DA EXPANSÃO URBANA INFLUENCIADA PELA INDÚSTRIA CERÂMICA EM SANTA GERTRUDES (SP)
}

\author{
Helton Henrique Alvarinho ${ }^{(a)}$; Andréia Medinilha Pancher ${ }^{(b)}$ Lucimari Aparecida Franco Garcia \\ Rossetti $^{(c)}$ \\ (a) Departamento de Planejamento Territorial e Geoprocessamento/Universidade Estadual Paulista / \\ helton.alvarinho@gmail.com \\ (b) Departamento de Planejamento Territorial e Geoprocessamento/Universidade Estadual Paulista / \\ medinilh@rc.unesp.br \\ (c) Centro de Análise e Planejamento Ambiental/Universidade Estadual Paulista / lucimari@ @rc.unesp.br
}

Eixo: Uso e ocupação das terras e legislação ambiental

\begin{abstract}
Resumo
O presente estudo teve por objetivo analisar o uso do solo urbano e a expansão da cidade no contexto do perímetro urbano de Santa Gertrudes, influenciados pela atividade ceramista do polo cerâmico Santa Gertrudes. Para o propósito, realizou-se consistente embasamento teórico e metodológico sobre a temática e a área de estudo, bem como foram elaborados mapeamentos relativos ao uso do solo urbano dos cenários de 1995 e de 2010, com apoio nas geotecnologias. Como resultados, ressalta-se que a atividade cerâmica tem exercido considerável influência no processo de expansão urbana e industrial de Santa Gertrudes. No período analisado, os usos que apresentaram maior crescimento foram: industrial (de $4 \%$ para $11 \%$ ), residencial (de $7,1 \%$ para $12 \%$ ) e vegetação (de $4 \%$ para $6,6 \%$ ); também, o uso do solo que apresentou maior redução foi cultura (de 50,6\% para 35,9\%).
\end{abstract}

Palavras chave: Uso do solo urbano; Expansão urbana; Geoprocessamento.

\section{Introdução}

No Brasil, ainda dependente dos interesses portugueses, a expansão da agricultura e mineração motivou uma revolução da urbanização, no século XVIII, e criaram as bases para o surgimento dos primeiros núcleos urbanos, as cidades administrativas, que inicialmente se concentraram no litoral, e que posteriormente foram se expandindo para o interior do país (SANTOS, 2009).

A grande revolução da urbanização no Brasil aconteceu na segunda metade do século XX, pois até 1950 ainda predominava uma população rural e um modelo agrário-exportador. Nesse período o país viveu a importante transição para o modelo urbano-industrial, que já era realidade em países mais desenvolvidos. O processo de industrialização transformou o país rural e agrícola num país urbano e metropolitano, causando a mudança da mão de obra do campo para as cidades e concentrando um contingente maior de pessoas nos núcleos urbanos. 
Em relação ao desenvolvimento econômico do Brasil, após a crise econômica mundial de 1929, houve uma nova política de recuperação econômica do país, quando o mercado interno ganhou importância, impulsionando o processo de industrialização (SANTOS, 2009). A partir de 1940, houve um período de forte crescimento econômico, sendo que os reflexos da segunda guerra mundial alavancaram ainda mais o processo de industrialização, e o país intensificou a urbanização. Segundo Cano, Semeghini e Araújo (1992), com um novo declínio da atividade econômica na década de 1960, causado pelo endividamento do governo, das famílias e empresas, o golpe militar de 1964 estabeleceu reformas para uma modernização do capitalismo no país, abrindo a economia para o capital estrangeiro.

Entre as décadas de 1970 e 1980 a nova base econômica industrial ativa um processo de urbanização cada vez mais intenso, desencadeando no aumento da concentração demográfica em cidades médias e nos grandes centros (metropolização) (SANTOS, 2009). Nesse período, o crescimento da população urbana já era maior que o da população rural, porém com muitas discrepâncias regionais. Enquanto a integração do território não havia se tornado um fenômeno generalizado, as grandes regiões do país apresentavam taxas desiguais de urbanização. Em 1980, as maiores taxas de urbanização abrangiam as regiões Sudeste $(82,79)$, Centro-Oeste $(67,75 \%)$ e Sul $(62,41 \%)$, enquanto que as regiões Norte $(51,69 \%)$ e Nordeste $(50,44 \%)$, caracterizavam-se pelas menores taxas do fenômeno.

A década de 1990 promoveu a integração econômica internacional por meio da globalização. A chegada das multinacionais concentradas em espaços selecionados, e privilegiados, impõe-se no território, influenciando as regras da economia e da sociedade, e consequentemente do sistema urbano. De acordo com o censo de 1991, a urbanização brasileira atingiu aproximadamente $75 \%$, contudo, apresentando uma tendência de queda de crescimento nas regiões metropolitanas. Essa alteração deveu-se ao processo de desconcentração industrial, que pode ser entendido nesse período basicamente pela crise econômica que afetou o país desde a década de 1980 até meados de 1990, e o processo de desconcentração produtiva (MARTINE; MCGRANAHAM, 2010).

No século XXI, o país entra em um processo de maturidade em sua transição urbana. A grande maioria da população brasileira agora vive nas cidades, em grandes redes urbanas, em um novo patamar de integração do território (MARTINE; MCGRANAHAN, 2010). Nessa fase do país, houve a recuperação econômica e investimentos na área social, com maior estabilidade monetária e fiscal e ampliação do setor industrial pelo aquecimento do mercado interno.

Nos últimos anos, observou-se no Brasil a desaceleração das grandes concentrações metropolitanas, com uma distribuição da população em diferentes espacialidades do sistema urbano brasileiro, havendo, portanto, um processo de interiorização das aglomerações urbanas (BAENINGER e PERES, 2011). 
Nesse contexto, o município de Santa Gertrudes se encontra num dos mais importantes eixos do desenvolvimento do interior paulista, as margens de uma das mais importantes rodovias do estado, com oferta de matéria prima para a produção cerâmica, além de apresentar índices de qualidade de vida melhores do que os das grandes metrópoles. Diante do exposto, esse trabalho teve como objetivo identificar e caracterizar o uso do solo urbano e analisar a expansão da cidade, considerando-se o limite do perímetro urbano do município de Santa Gertrudes SP, nos cenários de 1995 e 2010, com suporte das geotecnologias.

\section{Localização e Caracterização de Santa Gertrudes (SP)}

Santa Gertrudes situa-se no interior do Estado de São Paulo, entre as coordenadas UTM 235.000mE e 7.507.000mN; e, $246.500 \mathrm{mE}$ e $7.519 .000 \mathrm{mN}$ (figura 1). Também, faz parte da Região Administrativa de Campinas e da Mesorregião de Piracicaba, na porção centro-leste do Estado de São Paulo. Ocupa uma área de $98,3 \mathrm{~km}^{2}$ e segundo estimativa do IBGE (2016), abriga 25.192 habitantes (estimativa do IBGE, 2016), portanto, a densidade demográfica é de aproximadamente $256,3 \mathrm{hab} . / \mathrm{km}^{2}$.

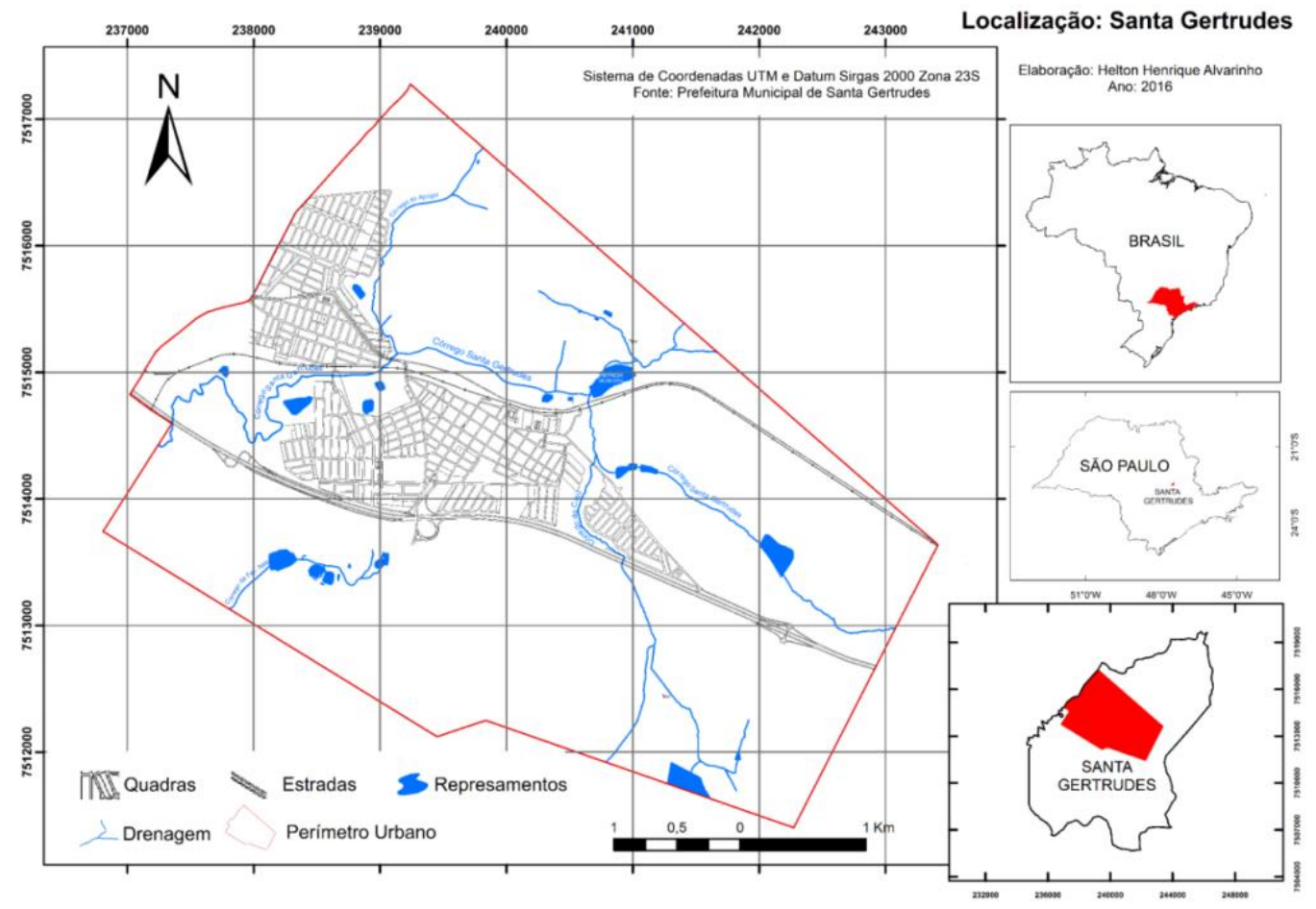

Figura 1 - Localização da área de estudo. Fonte: Alvarinho, 2016.

O município faz parte de uma das regiões mais desenvolvidas do interior do estado de São Paulo, sendo o principal do maior polo cerâmico da América Latina. O Índice de Desenvolvimento Humano Municipal é de 0,737 (IDHM 2010), compreendendo a classe com IDHM alto (entre 0,700 a 0,799). Localiza-se a 167 
quilômetros da capital São Paulo e possuí acesso através do entroncamento com a rodovia estadual Washington Luís, uma das rodovias mais importantes do Estado. Cabe salientar, que para a realização deste trabalho, foi considerado o perímetro urbano de Santa Gertrudes (Prefeitura Municipal de Santa Gertrudes, 2012).

O município de Santa Gertrudes teve origem na Fazenda Santa Gertrudes, que foi uma propriedade canavieira herdada pelo Barão de São João do Rio Claro, Sr. Amador de Lacerda Rodrigues Jordão, em 1848. A produção açucareira durou apenas duas ou três décadas; por volta de 1860, a região de Campinas e Rio Claro começam a transição para a cultura do café, muito mais promissora. A cultura do café começou utilizando a mão de obra escrava e após 1880 adotou o regime de trabalho livre, pelos imigrantes europeus, que contribuíram para o beneficiamento da produção do café e para o adensamento populacional, fundando assim os primeiros povoamentos próximos da fazenda. Um importante resultado da economia cafeeira foi a construção da ferrovia da Companhia Paulista de Estrada de Ferro, que ligava Jundiaí a Campinas, vindo até Rio Claro, aspecto de extrema importância para o crescimento da região. O desenvolvimento dos primeiros núcleos urbanos ocorreu no entorno da ferrovia. Durante as quatro primeiras décadas do século XX Santa Gertrudes deixa de ser um pequeno povoamento para se tornar em 1918, um Distrito do Município de Rio Claro. No final de 1948, desmembrada de Rio Claro, foi elevada à categoria de Município (GARCIA, 2003).

Cabe ressaltar que as atividades econômicas do município começaram a se diversificar ainda quando Santa Gertrudes era um distrito de Rio Claro, com a instalação de pequenas fábricas que produziam mercadorias consumidas pela própria população. Nesse período também se iniciava a atividade econômica mais famosa do município, a indústria cerâmica, que produzia telhas graças à grande oferta de matéria prima da região; a Buschinelli foi a primeira indústria cerâmica da cidade (GARCIA, 2003).

Entre 1950 e 1960 a cidade começa a receber importantes infraestruturas para sustentar o desenvolvimento urbano, serviço de água e esgoto; serviço telefônico; hospital; creche; escolas; pavimentação asfáltica; praças; e a construção do trevo para ligação com a Rodovia Washington Luís. Na década de 1970, a grande maioria das atividades econômicas e industriais do município se desenvolve na área urbana, a indústria cerâmica já era a atividade mais importante, porém, havia também destaque para a produção de óleos vegetais, tecelagem, fundição, criação de cavalos puro sangue e gado leiteiro (GARCIA, 2003, pág. 139-140).

Na década de 1980, 80\% dos trabalhadores da cidade eram ceramistas, sendo que a grande maioria havia aprendido os ofícios de trabalhar com cerâmica com o país e avós. Nesse período indústria cerâmica deu um salto, com o sistema de monoqueima em substituição da produção artesanal; em 1993, um moderno 
laboratório de análises trouxe uma maior competitividade para os pisos e revestimentos produzidos em Santa Gertrudes. Esse processo atraiu uma grande quantidade de trabalhadores do campo e de outros estados do Brasil se instalaram no local, juntamente com suas famílias (GARCIA, 2003).

Atualmente, Santa Gertrudes é o principal município do Polo Cerâmico, que também abrange as cidades de Araras, Charqueada, Cordeirópolis, Ipeúna, Iracemápolis, Limeira, Piracicaba e Rio Claro. Esse é o maior polo cerâmico da América Latina, produzindo $85 \%$ da produção do Estado de São Paulo, que corresponde a 70\% da produção nacional (ASPACER, 2016). Segundo dados da Prefeitura Municipal, em 2012 existiam 19 cerâmicas na cidade, sendo todas localizadas no perímetro urbano. Entre 1991 e 2000, período no qual o estado São Paulo estabelecia o crescimento da rede urbana nos eixos de desenvolvimento do interior, Santa Gertrudes, assim como muitas cidades médias e pequenas da região, registrou um aumento, em torno de 51\%, passando de 10.485 para 15.898 habitantes em 2000. Entre 2000 e 2010 essa taxa caiu um pouco, para 36\%, e o município ultrapassou os 20 mil habitantes, chegando a 21.634, sendo 18.607 pessoas da área urbana e 189 da zona rural (IBGE, 2010).

\section{Procedimentos Metodológicos}

Os procedimentos metodológicos adotados no trabalho visaram identificar e caracterizar o uso do solo urbano e analisar a expansão da cidade, considerando-se o limite do perímetro urbano do município de Santa Gertrudes SP, nos cenários de 1995 e 2010. Assim, o estudo envolveu o embasamento teórico e metodológico relativo à temática e a área de estudo, bem como a elaboração e a análise de mapas temáticos de uso do solo urbano no período, utilizando-se recursos do SIG ARCGIS.

\subsection{Levantamento de dados cartográficos e bibliográficos}

A etapa do levantamento dos dados cartográficos e bibliográficos permitiu o conhecimento das características da área de estudo, bem como a fundamentação teórico-metodológica que subsidiou este trabalho. Assim, foram selecionadas imagens aerofotogramétricas analógicas (1995) e ortofotos (2010) para realizar o mapeamento do uso do solo urbano.

\subsection{Mapeamento do Uso do Solo Urbano}


Para o mapeamento do uso do solo urbano foi necessário realizar procedimentos de pré-processamento das imagens aerofotogramétricas analógicas de 1995, com a finalidade de prepará-las para à fotointerpretação e mapeamento manual. Os procedimentos de pré-processamento das imagens, estão descritos a seguir:

\section{a) Conversão das Imagens Aerofotogramétricas Analógicas para Digitais}

As imagens aerofotogramétricas analógicas de 1995, na escala de 1:25.000, foram digitalizadas em scanner de alta resolução (A0), no formato tif, para serem manipuladas no ambiente do SIG ARCGIS.

\section{b) Georeferenciamento}

Para compor a área de estudo, compreendida pelo perímetro urbano de Santa Gertrudes, foi necessário utilizar 2 imagens aerofotogramétrias; essas foram georreferenciadas adotando-se o sistema de coordenadas UTM e o Datum SIRGAS 2000, Zona 23S, com base na Ortofoto de 2010. Foram selecionados entre 7 e 8 pontos de controle nas imagens aerofotogramétricas (1995) e seus pontos homólogos foram inseridos na imagem de referência (Ortofoto, 2010). Cabe destacar, que os pontos de controle foram regularmente distribuídos, o que permitiu atingir o Padrão de Exatidão Cartográfica (PEC) Classe A (média de erro de 3,64m).

\section{c) Mapeamentos temáticos do Uso do Solo Urbano: cenários de 1995 e 2010}

Para o mapeamento de uso do solo urbano foram considerados dois cenários: de 1995, anterior ao intenso desenvolvimento do polo cerâmico; e, de 2010, de considerável desenvolvimento da indústria cerâmica e de intenso crescimento urbano. Em razão da alta resolução espacial das imagens aerofotogramétricas e das Ortofotos digitais, e do elevado nível de detalhe necessário para a análise deste trabalho, optou-se pela fotointerpretação e pelo mapeamento manual das feições presentes nas imagens.

Ressalta-se, que os dados vetoriais relativos à drenagem, limite do perímetro urbano, estradas, ferrovia, quadras, foram obtidos a partir da planta cadastral digital (.dwg) do município de Santa Gertrudes (2012), fornecida pela Prefeitura Municipal. A planta cadastral também foi georreferrenciada no sistema de coordenadas UTM, Datum Sirgas 2000, Zona 23. Utilizando-se os recursos de desenho e edição do ArcGIS, foi possível ajustar a planta original e selecionar layers necessários ao estudo.

Após a análise interpretativa das imagens e trabalho de campo, e a fim de contemplar o nível de detalhamento necessário para distinção das classes temáticas, optou-se por um sistema de classificação independente, onde foram definidas 11 classes de uso do solo urbano: 1) Campo (áreas com gramíneas e vegetação arbustiva), 2) Complexo viário, 3) Cultura (cana de açúcar, e outras culturas), 4) Industrial, 5) 
Institucional (praças, estação ferroviária, áreas de lazer públicas, prefeitura, escolas e hospitais), 6) Loteamento, 7) Represamento, 8) Residencial, 9) Sítio/Chácara, 10) Solo Exposto e 11) Vegetação (mata nativa e de reflorestamento). Os polígonos correspondentes a cada classe temática foram vetorizados manualmente, organizados em camadas (layers) e em arquivos vetoriais (shapefiles).

Com base no mapa de uso do solo urbano, calculou-se a área $\left(\mathrm{m}^{2}\right)$ e a proporção $(\%)$ ocupada por cada classe temática. A esse mapa temático, foram adicionados os dados vetoriais das quadras, estradas e drenagem, relevantes a análise do uso do solo urbano.

\section{Resultados e Discussões}

A mancha urbana de Santa Gertrudes possui um formato alongado, no sentido leste - oeste, ocupando a área entre a ferrovia e a rodovia Washington Luiz. Nos cenários de 1995 e 2010, verificou-se que a expansão da cidade se intensificou e esse processo foi evidenciado pelo crescimento dos bairros existentes e pelos loteamentos observados nas porções noroeste, sudoeste e sul da mancha urbana.

\subsection{Análise do uso do Solo Urbano: cenário de 1995}

Em Santa Gertrudes, a indústria cerâmica teve um crescimento significativo desde a década de 1990. Em razão dos investimentos em tecnologia, os produtos cerâmicos se tornaram mais competitivos e ganharam mais mercado nacional e internacional. No período de 1980 a 1996, o município apresentou um aumento populacional de 100\%, enquanto que entre 1991 e 1996 o aumento da população foi de 36\%. Com base nos dados do IBGE (1996) o município possuía 13.605 habitantes, sendo 13.206 urbanos (97\% da população total) e 399 rurais. A densidade demográfica era de 138,41 hab./ $\mathrm{km}^{2}$, contudo, se fossem considerados o perímetro urbano e a população urbana para o cálculo da densidade demográfica, essa variável seria bem mais elevada (631,20 hab./km²) (IBGE, 1996).

Analisando-se o mapa de Uso do Solo Urbano (Figura 2), observa-se que a região densamente urbanizada se encontra na parte central da cidade e que as classes cultura (50,6\%), campo $(21,0 \%)$ e residencial $(7,1 \%)$ são predominantes. É relevante salientar, que o uso cultura ocupa todo o entorno da área edificada, denotando a transição entre o urbano e o rural. Também, o uso industrial $(4,6 \%)$ se distribui de modo contíguo à área edificada. Conforme Garcia (2003), nesta área, concentraram as primeiras ocupações urbanas do município, próximas da linha férrea, e em frente da estação ferroviária.

Conforme a figura 2, observa-se alguns eixos de crescimento identificados pela presença de 3 loteamentos $(0,5 \%)$ próximos das áreas residenciais, sendo 2 a noroeste, e 1 as margens da rodovia Washington Luís 
conectada ao centro. A porção noroeste da área urbana de Santa Gertrudes consiste na área de expansão mais recente, localizada entre o limite do município de Rio Claro e o córrego Santa Gertrudes. Essa proximidade da área urbana recente de Santa Gertrudes com o limite do município de Rio Claro evidencia o processo de conurbação.
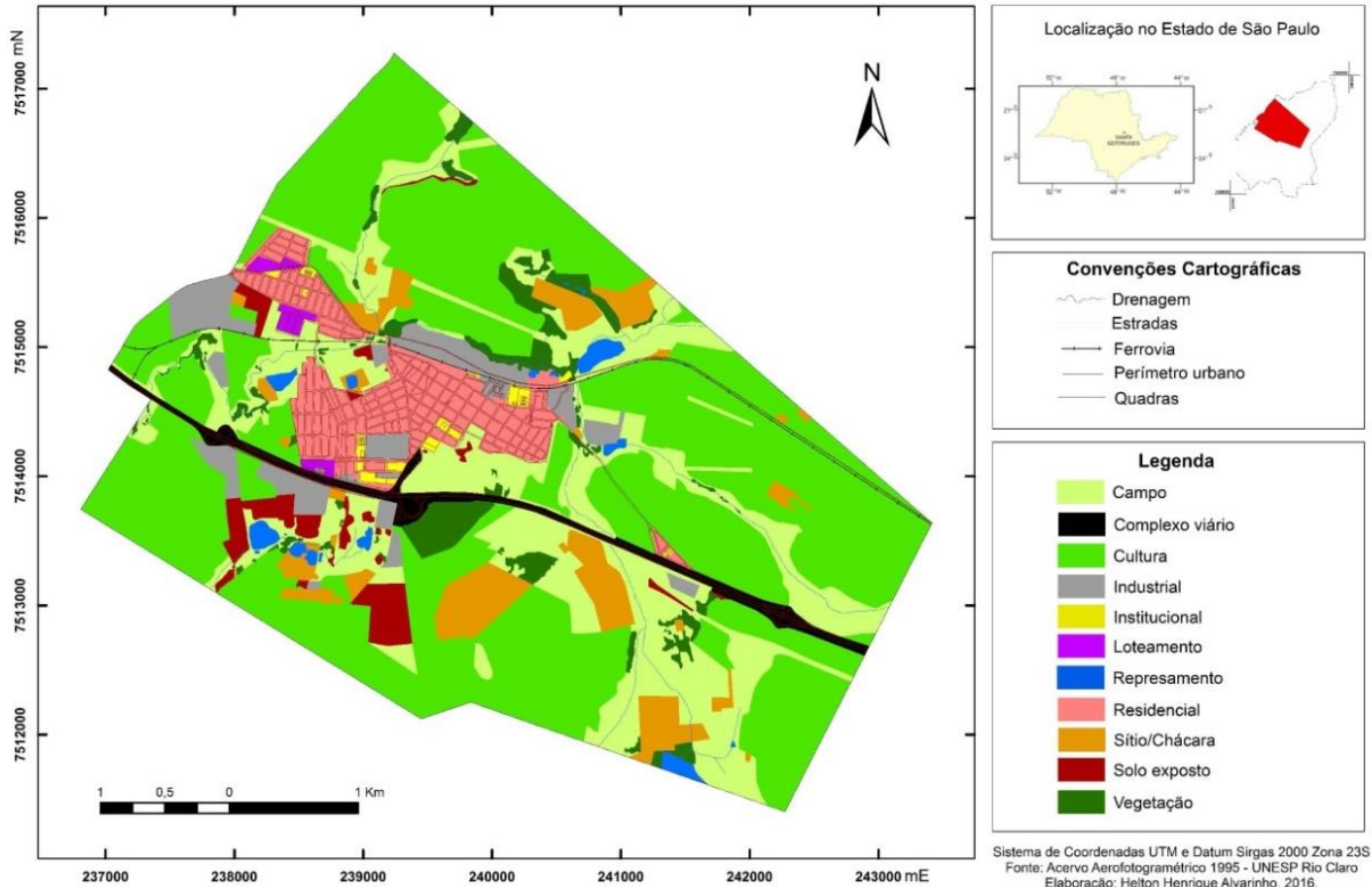

Figura 2 - Uso do Solo Urbano - Santa Gertrudes SP - 1995

Vale salientar ainda, o bairro Santa Catarina no setor sudeste, desconectado da malha densamente urbanizada, localizado nas margens da rodovia Washington Luís (sentido Cordeirópolis), que se integra à cidade por uma via de acesso (Avenida Conde Guilherme Prates). Observa-se que entre esse bairro (Santa Catarina) e a região central, há uma extensa área com o predomínio dos usos campo e cultura, além da presença de uma escola no centro do bairro, representativa da classe de uso institucional. Ainda, nota-se que a área entre o referido bairro e a malha urbana densa é interceptada pelo córrego do Cajú. A figura 3 evidencia as proporções (\%) das classes de uso do solo urbano do cenário de 1995.

A área urbana é compreendida predominantemente pelas classes residencial $(7,1 \%)$ e Industrial $(4,6 \%)$ e, em menor proporção, pela Institucional $(0,6 \%)$. No caso das indústrias, destacam-se as cerâmicas, que desde o século XX se aglomeraram próximas da ferrovia, na parte central da cidade, se expandindo posteriormente nas margens da rodovia Washington Luís, entre os trechos do km 164 e km 169 (GARCIA, 2004). 


\section{USO DO SOLO URBANO - 1995}

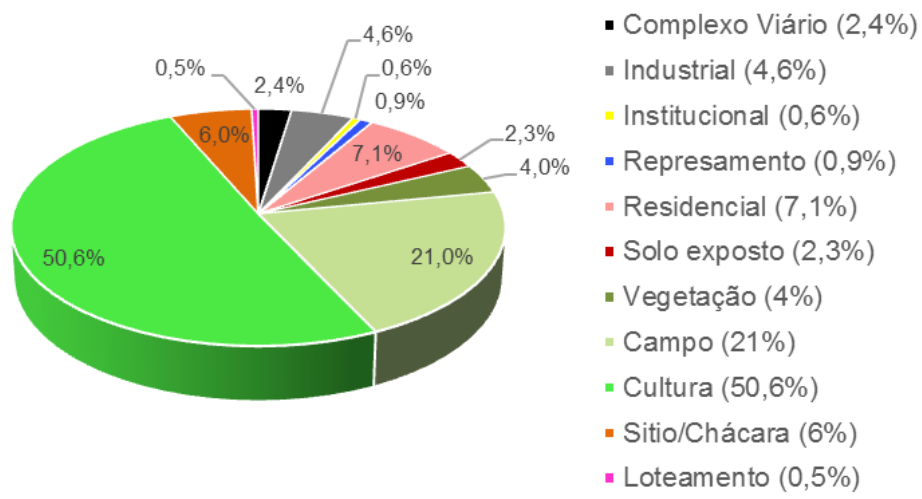

Figura 3 - Classes de Uso do Solo Urbano - 1995. Fonte: Alvarinho, 2016.

No que se refere ao uso cultura $(50,6 \%)$, destaca-se o cultivo de cana-de-açúcar, que ocupa cerca da metade da área do perímetro urbano. Outra classe de uso expressivo na área analisada corresponde ao campo (21\%), que abrange principalmente as áreas do entorno dos cursos d'água e das proximidades da mancha urbana. Observa-se que na classe sítio/chácara $(6 \%)$, as áreas mais extensas ocupam principalmente os setores Nordeste, Sul e Sudeste, próximas das classes de uso cultura, campo e vegetação, bem como dos cursos d'água; ainda, há também pequenas porções de sítio/chácaras, que se localizam próximas a malha urbana.

A classe vegetação (4\%), relativa à mata nativa e de reflorestamento, se concentra em áreas próximas do córrego Santa Gertrudes, em alguns sítios e fazendas, e em uma área de reflorestamento às margens do viaduto principal que liga Santa Gertrudes a rodovia Washington Luís. Nas proximidades dos córregos, também se observa a presença da classe de uso campo (pastagens, arbustivas esparsas). Com relação ao uso solo exposto (2,3\%), no perímetro urbano, as maiores áreas ocupadas por essa classe estão próximas das indústrias cerâmicas, ou seja, nos locais de extração e de secagem das argilas da Formação Corumbataí.

\subsection{Análise do uso do Solo Urbano: cenário de 2010}

O cenário de 2010 (figura 4) revela as alterações nos usos do solo urbano, com ênfase ao crescimento da classe residencial, de $7,1 \%$ para $12 \%$, principalmente na direção noroeste, área conurbada com o município de Rio Claro; o uso residencial também se expandiu na parte central do município avançando em direção ao sul, próxima às margens da Rodovia Washington Luís, e também na direção Oeste, paralela à rodovia. A classe industrial apresentou um considerável aumento, de 4,6\% para 11,6\%, envolvendo 
XVII Simpósio Brasileiro

de Geografia Física Aplicada

I Congresso Nacional de Geografia Física
OS DESAFIOS DA GEOGRAFIA FISICA NA FRONTEIRA DO CONHECIMENTO

Instituto de Geociências - Unicamp

Campinas - SP

28 de Junho à 02 de Julho de 2017

essencialmente as cerâmicas, ocupando o entorno da área urbana. Apesar de não atender a legislação relativa ao Código Florestal (Lei n ${ }^{\circ} 12.651 / 2012$ ), a vegetação aumentou no período analisado, de 4\% para $6,6 \%$. A classe campo reduziu de $21 \%$ para $20,4 \%$, sendo substituída pelos usos cultura, industrial e residencial (figura 5).
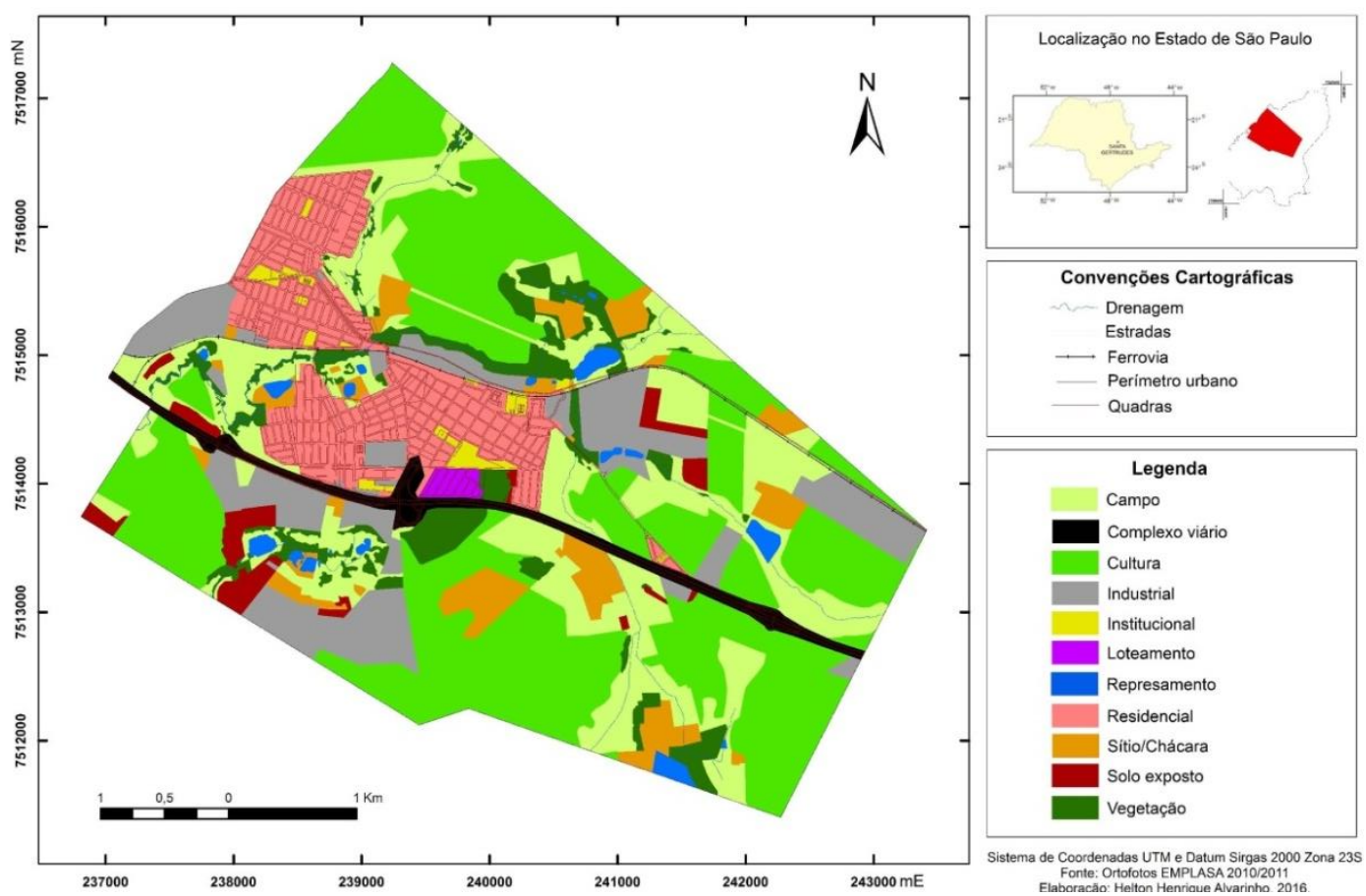

Figura 4 - Uso do Solo Urbano - Santa Gertrudes SP - 2010. Fonte: Alvarinho, 2016.

\section{PORCENTAGEM DE USO DO SOLO URBANO - 2010}

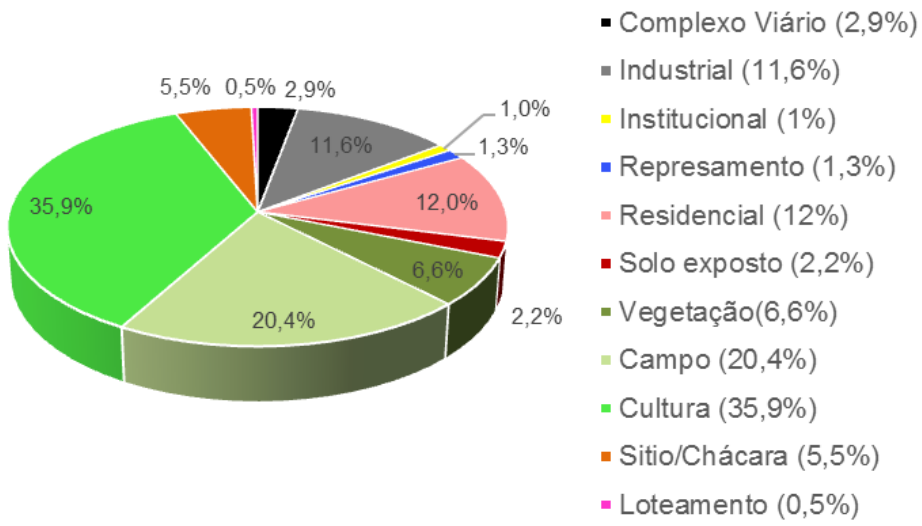

Figura 5 - Classes de Uso do Solo Urbano - 2010. Fonte: Alvarinho, 2016. 
No cenário de 1995, foram identificadas três áreas na classe de uso loteamento. Na década de 2010, duas dessas áreas foram modificadas para uso residencial, e uma delas para uso institucional, já que foi construída uma área de lazer na parte noroeste da cidade, próxima aos bairros que mais se expandiram.

Analisando-se os dados da figura 5, observa-se a redução do uso cultura (35,9\%) e o aumento das classes de uso residencial (12\%) e industrial $(11,6 \%)$. Tais dados, associados ao mapa de uso do solo urbano, revelam a pressão exercida pelas classes de uso residencial e industrial em áreas antes ocupadas pela agricultura. As indústrias aumentaram consideravelmente, de 4\% e em 1995 para 11\% em 2010, avançando nas áreas de uso cultura e solo exposto (antigas áreas de extração e secagem de argila), e que passaram a ser utilizadas para a expansão das indústrias cerâmicas. A classe de uso solo exposto $(2,2 \%)$ também aumentou e se localiza próximas das indústrias cerâmicas. Em 2010, nota-se somente um loteamento na porção Sul, localizado numa área de expansão limitada pela rodovia Washington Luís. Também se percebe a tendência à concentração das indústrias na parte sul do território urbano, separada da região central pela rodovia Washington Luís. Essa região é um distrito industrial onde várias cerâmicas estão se aglomerando e expandindo suas unidades produtivas. O tecido industrial também avança no sentido nordeste e leste, onde é possível localizar grandes cerâmicas.

A classe vegetação também aumentou no período (de 4\% para 6,6\%), principalmente as matas ciliares, nas áreas onde o córrego Santa Gertrudes atravessa o núcleo urbano e as indústrias. O aumento também ocorreu próximo às propriedades rurais. De maneira geral, a vegetação se expandiu em áreas que antes eram ocupadas pela classe campo $(20,4 \%)$.

\section{Considerações Finais}

A análise do uso urbano e da expansão da cidade é importante para o conhecimento da intensidade e dos reflexos desse processo num determinado território, subsidiando a tomada de decisões para solucionar e/ou amenizar problemas já existentes, bem como para o adequado planejamento das atividades antrópicas, visando evitar consequências mais graves em cenários futuros. Para estudos dessa natureza, o uso das geotecnologias é fundamental, pois permite ao planejador avaliar de modo consistente áreas com características complexas, integrando-se dados de diversas fontes e processando-os de forma rápida com um custo muito reduzido.

Ao espacializar o uso do solo urbano de Santa Gertrudes, considerando-se os cenários (1995 e 2010) e quantificar as alterações nas classes de uso, verificou-se que a malha urbana da cidade e a área industrial estão em expansão dentro do perímetro urbano. No período de 1995 a 2010, observou-se que a expansão da malha urbana ocorreu em três eixos: Noroeste, área conurbada com o município de Rio Claro; a Oeste e 
ao Sul, as margens da Rodovia Washington Luís. Assim, no período analisado, notou-que as indústrias se desenvolveram no entorno imediato da malha urbana e as margens da rodovia Washington Luís, formando distritos industriais nas porções sul e nordeste.

As técnicas de Geoprocessamento e as imagens orbitais de Sensoriamento Remoto permitiram espacializar o uso do solo urbano, quantificar e realizar uma análise multitemporal da expansão urbana. Os mapas de uso do solo urbano de 1995 e 2010 evidenciaram a expansão da malha urbana e da área industrial no perímetro urbano, em um território que ainda possui propriedades rurais e que tem a maior parte de seu uso atividades agrícolas.

O perímetro urbano apresenta poucas áreas de especulação fundiária, pois as áreas indicadas para a expansão urbana são utilizadas (ocupadas) na agricultura. $\mathrm{O}$ crescimento não ocorre em função das atividades econômicas primárias, as áreas de expansão das cerâmicas determinam ritmo do crescimento. A indústria cerâmica proporcionou a geração de empregos e crescimento econômico. Porém, atividade causou exploração dos recursos naturais, o desequilíbrio dos ecossistemas e um crescimento urbano desordenado, com perda de qualidade de vida para a população.

\section{Bibliografia}

ALVARINHO, H. H. O uso das Geotecnologias para Análise de Expansão Urbana de Santa Gertrudes/SP. Trabalho de Conclusão de Curso (Bacharelado em Geografia), Rio Claro: IGCE/UNESP, 2016.

ASSOCIAÇÃO PAUlista DAS CERÂMICAS DE REVESTIMENTO. Dados do Polo Cerâmico Santa Gertrudes SP. Disponível em: http://www.aspacer.com.br. Acesso em: junho de 2016.

BAENINGER, R.; PERES, R. G. Metrópoles Brasileiras no Século 21: Evidências do Censo Demográfico de 2010 - Toledo, Informe Gepec, v.15, número especial, 2011.

CANO, W.; SEMEGHINI, U. C.; ARAÚJO, A. R. F. Análise regional do setor de serviços no Estado de São Paulo. In: SÃO PAULO (Estado). Secretaria de Planejamento e Gestão. Fundação SEADE. Diagnósticos setoriais da economia paulista: setores de indústria e serviços. São Paulo: SEADE, 1992. (Coleção São Paulo no Linear do Século XXI, v.3).

GARCIA, L. B. dos R. O Passado e o Presente: Santa Gertrudes Seu Povo e Sua História. Rio Claro, 2003.

IBGE. Censo Demográfico de 2010. Disponível em: www.cidades.ibge.gov.br/xtras/perfil.php. Acesso: junho de 2016.

MARTINE, G.; MCGRANAHAN, G. A transição urbana Brasileira: trajetórias, dificuldades e lições aprendidas. In: BAENINGER, R. (Org.). População e Cidades subsídios para o planejamento e para as políticas sociais. Campinas: Núcleo de Estudos de População-Nepo/Unicamp; Brasília: UNFPA, 2010, p. 11-24.

SANTOS, M. A Urbanização Brasileira, 5ª ed., 2. Reinpr. Edusp, São Paulo, 2009. 